\title{
MULHER IDOSA: a feminização da velhice ${ }^{1}$
}

\author{
Carmen Delia Sánchez Salgado²
}

\section{Resumo}

Como resultado da desigualdade de gênero na expectativa de vida, existe uma maior proporção de mulheres do que de homens com idade avançada. Os problemas e mudanças que acompanham essa etapa de vida são predominantemente femininos, pelo que se pode dizer que a velhice se feminilizou. As mulheres são discriminadas por preconceitos sexistas e gerofóbicos: não só por serem mulheres, mas também por serem velhas. Este artigo discute aspectos em que as mulheres se vêem afetadas quando envelhecem, tais como: discriminação e gerofobia, pobreza e solidão, mudanças e perdas físicas e sociais. Apresenta, ainda, os aspectos positivos de ser mulher e idosa.

Palavras-chave: Mulher; Velhice; Feminismo.

\begin{abstract}
As a result of the inequality of gender in life expectancy, there is a higher proportion of women than men in old age. The problems and changes that take place in this stage of life are basically womens problems so it can be stated that aging is a womens issue. Women face prejudices nor only for being women but also for being old, sexist and ageist prejudices. This article discusses areas in which women are affected as they aged such as: discrimination and ageism, poverty and loneliness, physical and social losses and changes. It will also present the positive aspects of being old and female

Keywords: Women; Aging; Feminism.
\end{abstract}

\footnotetext{
${ }^{1}$ Tradução de Sergio Antonio Carlos; revisão de Breno Serafini.

${ }^{2}$ Assistente Social, Professora Graduada de Trabajo Social, Recinto de Rio Piedras, Universidad de Puerto Rico, San Juan - Puerto Rico. Doutora em Serviço Social. E-mail: csanche@upracd.upr.clu.edu 


\section{Introdução}

O envelhecimento da população mundial é um fenômeno relativamente recente. Uma população envelhece quando se registra um aumento considerável da proporção de pessoas classificadas como de idade avançada no total dessa população. $\mathrm{O}$ índice comumente utilizado é a proporção da população idosa, de 65 anos ou mais. Uma proporção de $10 \%$ ou mais da população indica a presença de uma estrutura velha, em relação à idade. Para o ano 2000, a população mundial de 65 anos ou mais alcançou a cifra de 418 milhões, ou $6,6 \%$ da população mundial total. A idade mediana, em nível mundial, aumentou de 23,5 em 1950 para 26,8 em 1998, projetando-se para 2050 que essa idade estará em 37,8 (Nações Unidas, 1998). No mundo, em geral, existe uma proporção maior de mulheres idosas do que de homens, quando se considera a população total de cada sexo. Existe um excedente, portanto, de mulheres idosas em relação aos homens em idade avançada.

Como resultado de uma desigualdade de gênero na expectativa de vida, existe essa proporção maior de mulheres do que de homens nesse grupo populacional. As mulheres vivem, em média, sete anos mais do que os homens e estão vivendo mais do que nunca. Outra característica deste grupo populacional é que existe uma maior proporção de viúvas do que em qualquer outra faixa etária. Uma razão que poderia explicar essa situação é que, por tradição, a mulher tende a se casar com homens mais velhos do que ela, o que, associado a uma mortalidade masculina maior do que a feminina, aumenta a probabilidade de sobrevivência da mulher em relação ao seu cônjuge. Outra explicação do fenômeno de um maior número de mulheres viúvas nessa faixa etária é o fato de que os viúvos voltam, mais do que as viúvas, a se casar depois de enviuvar. Essa situação é a mesma para os divorciados.

A idade e o gênero sexual são dois dos principais fatores apontados pelos demógrafos ao estabelecerem diferenças entre membros da população. A presença de um grande número de mulheres em idade avançada é, em muitas sociedades, um fenômeno demográfico recente. A maior expectativa de vida das mulheres e a tendência destas em se casar com homens mais velhos trouxe como consequiência que, nas famílias, a maioria das pessoas de idade avançada sejam do sexo feminino. Hoje 
em dia, em países desenvolvidos, as mulheres que chegam aos 65 anos podem esperar viver, em média, mais 18 anos. Devido aos ganhos em longevidade em faixas etárias mais velhas se incrementarem mais nas mulheres do que nos homens, as mesmas estão claramente em maioria. Qualquer análise sobre longevidade indica claramente que, em relação à sobrevivência, as mulheres são o sexo mais forte. O mundo contemporâneo do adulto de idade avançada, bem como o futuro, é e será predominantemente um mundo de mulheres. $\mathrm{O}$ aumento da longevidade ocorrido na população em nível mundial implica a existência de mais de uma geração de velhos(as) em uma mesma família, e as projeções demográficas indicam que no, futuro, essas gerações estarão compostas, principalmente, por mulheres velhas que, possivelmente, estejam cuidando de suas velhas mães ou avós.

As mulheres de idade avançada enfrentam muitos desafios gerados por leis e políticas sociais de uma sociedade sexista e gerofóbica. As crenças sexistas e gerofóbicas refletem a ênfase da sociedade na produtividade, no atrativo sexual e físico. O contexto social atual ensina e perpetua o descrédito na mulher idosa, começando com a representação da mulher velha nas histórias clássicas como bruxas, feias e malvadas (LESNOFF-CARAVAGLIA, 1984). A mulher idosa é universalmente maltratada e vista como uma carga. É parte de uma maioria invisível cujas necessidades emocionais, econômicas e físicas permanecem, em sua maioria, ignoradas.

Pode-se assinalar, sem dúvida, que a velhice se feminilizou, converteu-se em um assunto de mulheres. $\mathrm{O}$ fato mais significativo e simples sobre a velhice é que a população idosa é predominantemente feminina. As mulheres idosas enfrentam uma problemática muito particular na sociedade atual, o que as coloca, em uma posição de fragilidade e de vulnerabilidade. Diferem de outros grupos de idade quanto ao nível de educação formal (escolaridade), tendo normalmente menos anos completos de escola do que outros grupos. Geralmente possuem menor qualificação profissional para conseguir emprego do que os grupos mais jovens e do que os grupos de homens idosos. Diferem em relação ao estado civil, sendo na sua maioria, viúvas e, portanto, muitas vezes, chefes de família. Chegam a uma idade em que a probabilidade de doenças de cuidado prolongado é maior (MEHDIZADEH, 2002). Encontram-se, 
muitas vezes, em uma situação de dependência de seus familiares, amigos(as) ou sistemas formais de serviços, mais do que qualquer outra faixa etária.

Pinquart e Sorensen (2001) ao estudarem as diferenças de autoconceito e bem estar psicológico em relação ao gênero, em um grupo de velhos(as) norte americanos, encontrou que, pelo fato de as mulheres terem maior risco de enviuvar, de apresentarem problemas de saúde e da necessidade de cuidado possuem, em geral, um autoconceito mais baixo do que o dos homens. Aponta cinco razões pelas quais as mulheres idosas teriam um bem-estar subjetivo menor. Em primeiro lugar, a desvantagem quanto a recursos de saúde (alta taxa de morbidade, necessidade de maior cuidado da saúde na velhice). Em segundo lugar, a maior possibilidade de enviuvar antes do que o homem (nos Estados Unidos essa possibilidade é três vezes maior para a mulher). Em terceiro lugar, a mulher idosa tem, em média, menos recursos materiais do que o homem (história de trabalho instável, menor aposentadoria e maior pobreza). Em quarto lugar os autores consideram que as mulheres idosas mostram sentimentos negativos mais freqüentemente do que os homens. Finalmente, na medida em que aumenta a idade, a mulher é considerada menos atrativa e, portanto, desvalorizada (enquanto que o homem ganha prestígio com a idade), o que a leva a uma menor auto-estima.

Os problemas ou mudanças que acompanham ou surgem na etapa da velhice (doenças crônicas, recursos econômicos insuficientes, necessidades de atenção ou cuidado, sobrevivência a amigos próximos e a familiares, entre outros) são, predominantemente, problemas femininos. Em nível psicológico e social, à mulher é atribuído, no transcurso de sua vida, uma série de responsabilidades na família e na sociedade em geral, que chegam com a velhice e nesses momentos, se acrescentam a ela. A mulher enfrenta, então, uma aposentadoria com rendimento mínimo ou nulo, escassos recursos econômicos, viuvez ou separação do casal, afastamento de seus filhos e filhas, cuidado de familiares dependentes (jovens ou idosos). Enfrenta, ainda sentimentos de inutilidade, provocados por todos os mitos e estereótipos existentes socialmente. Ou seja: "a não aceitação da velhice", a negação de sua sexualidade; "porque já não estou para isto"; uma baixa auto-estima porque: "já fisicamente não me vejo como antes", quando as estruturas sociais exigem da mulher ser 
jovem, bonita e produtiva para participar e contribuir com a sociedade. Isso vem acompanhado do agravante que os(as) formuladores(as) de política pública e os investigadores(as) sociais são predominantemente homens, que têm passado por cima das considerações específicos da mulher idosa.

$\mathrm{O}$ aumento da longevidade da mulher trouxe consigo um prolongamento dos papéis normais de adulto, o acréscimo de papéis novos e a flexibilidade de outros no curso da vida. Uma mulher que teve seus filhos ou filhas com a idade de 20 anos pode ser mãe por 50 ou 60 anos. Ainda que, na visão tradicional, desempenhe suas tarefas de mãe somente nos primeiros 20 anos, sempre será considerada mãe, já que o aumento de sua longevidade ampliará esse papel. Ampliará também seu papel de filha, já que seus pais viverão por mais tempo. A aposentadoria, que atualmente corresponde a mais de um quarto da vida de um adulto, provoca a criação de novas funções para a mulher idosa (CALASANTI, 1996).

\section{Situações Enfrentadas pela Mulher na Velhice}

A seguir descrever-se-ão mais detalhadamente situações que a mulher enfrenta na velhice.

\subsection{Discriminação pela Idade (gerofobia ou "ageism")}

A gerofobia é o termo que se usa para descrever os preconceitos e estereótipos, em relação às pessoas idosas, fundados unicamente em sua idade (BUTLER; LEWIS; SUDERLAND, 1991). Acredita-se que essas atitudes negativas surgem do medo que as gerações jovens têm do envelhecimento e de sua resistência em lidar com os desafios econômicos e sociais que estão relacionados ao aumento da população idosa. Para entender como o fenômeno da discriminação por idade (ou gerofobia) afeta às mulheres idosas, deve-se olhar também o sexismo. O preconceito de idade enfrentado pelas mulheres ao envelhecer está composto pelo sexismo e pela dupla mensagem que considera velha a mulher com idade inferior à do homem. Essa dupla mensagem da velhice leva a aceitar a visão de que enquanto os homens de idade avançada são "durões, rudes e viris", 
as mulheres estão "enrugadas". Os cabelos brancos e a calvície que fazem os homens parecerem "distintos e muito atrativos", mostram uma mulher em "decadência". A cultura hispano-americana, particularmente, vê a sexualidade da mulher idosa como fonte de humor - "grotesca, inapropriada". Tal preconceito surge, em parte, ao igualar erroneamente a sexualidade feminina a sua capacidade reprodutiva. Portanto, não é errado assinalar que essa discriminação para com a mulher idosa está intimamente ligada ao sexismo e é a extensão lógica da insistência de que as mulheres valem na medida em que são atrativas e úteis ao homem. A sobrevivência da mulher, tanto física quanto psicológica, tem sido vinculada à habilidade de corresponder ao homem e aos padrões sociais estabelecidos que reforçam constantemente o poder que emana do patriarcado. A ironia disto é que, as mulheres, incluindo as feministas, incorporaram em seu psiquismo a auto aversão que emana de não satisfazer plenamente essa norma arbitrária. Dentro deste contexto, tendo passado parte de sua vida nesse esforço de corresponder às expectativas do que é belo, a proximidade da velhice resulta ameaçadora e temida.

Algum dia toda mulher será idosa, caso viva o suficiente para sêlo. A maioria desejaria viver uma longa vida, porém a sociedade atual não valoriza nem a velhice nem o ser idoso e tende a separar as pessoas por idade e por gerações. As mulheres, portanto, têm sido socializadas e treinadas para temer a velhice. Negando o próprio processo de envelhecimento, pretende-se escapar das penalidades impostas à velhice. Sabese que, em uma sociedade, é melhor ser homem do que ser mulher, ser jovem do que ser velho, portanto ser mulher e ser velha é duplamente desvalorizado (SÁNCHEZ, 1998).

Simone de Beauvoir, em um de seus mais profundos textos, $A \mathrm{Ve}$ lhice, reflete de uma maneira realista e objetiva, quase agressiva, sobre a velhice, esse estado do ciclo de vida que à maioria dos seres humanos assusta e que a sociedade ensina a rejeitar. Simone assinala que: "[. . . ] a velhice não é uma conclusão necessária da existência humana, apesar de que é uma verdade empírica e universal que a partir de certo número de anos o organismo humano sofre uma regressão. Ao final de certo tempo acarreta uma redução das atividades do sujeito, muitas vezes uma mudança de sua atitude em relação a si mesmo e em relação ao mundo." (BEAUVOIR, 1990). 
A adaptação ao processo de envelhecimento traz dificuldades individuais para as quais cada mulher desenvolve sua própria estratégia de adaptação. É no contexto externo (a sociedade e suas expectativas) que se agravam os problemas inerentes à adaptação (LESNOFFCARAVAGLIA, 1984). Para ser notada, uma mulher idosa tem que ser um personagem famoso, alguém como Helena Rubinstein, que, apesar de seus mais de noventa anos, dirigiu com êxito uma empresa de cosméticos, ou como artistas de cinema. Apesar de tanto os homens quanto as mulheres serem vítimas da discriminação por idade, a mulher idosa é particularmente desvalorizada, não só por ser velha mas também por ser mulher.

\subsection{Pobreza e Solidão}

A pobreza é, também, sinônimo de desigualdade, privação ou necessidade. Em termos gerais, identificou-se a população idosa como pobre pela definição social comum da saída do mundo do trabalho e da entrada em um mundo de recompensas, aposentadorias ou serviços sociais. $\mathrm{O}$ acesso à aposentadoria produz, em si, uma diminuição maior ou menor dos rendimentos em relação à vida ativa, diminuição esta regida pelos rendimentos mínimos necessários para a subsistência, o que faz com que tenha uma posição desfavorável em relação ao restante da população. Quando uma pessoa idosa começa a viver no limite da pobreza tem muito menos possibilidade de escapar dessa situação do que outra de qualquer faixa etária. A pobreza na idade avançada tende a aumentar a dependência produzida por condições físicas e psicológicas. A relação entre dependência, pobreza e velhice adquire maior importância em relação à distribuição de recursos econômicos individuais e a disponibilidade de serviços sociais. As diferenças de gênero tornam a situação mais crítica. As pesquisas gerontológicas mostram que são as mulheres de idade avançada (e não os homens) que estão mais expostas à pobreza e à solidão e que também detêm taxas mais altas de institucionalização, mais condições de morbidade, que consultam mais médicos e que têm menos oportunidades de contar com um companheiro em seus últimos anos de vida (TURNER; TROLL, 1994; GREENBERG; KOPITO, 1994). Após uma vida sem receber rendimentos ou salários adequados, não é aciden- 
tal que a mulher, na velhice, seja mais pobre que o homem. Apesar de muitas mulheres de idade avançada precisarem suprir certas necessidades básicas, enfrentam mais a pobreza do que quando eram jovens. Entre as razões que se pode assinalar para este fato, cita-se: não se dá compensação, reconhecimento ou direito à aposentadoria a mulheres cujo trabalho tenha sido primordialmente doméstico; devido à discriminação sexual, as mulheres ganham menos e, por esta razão, as aposentadorias são mais baixas; caso decidam voltar a trabalhar, não são admitidas por falta de experiência recente ou pela idade; muitas não têm direito à pensão de seus maridos por serem muito jovens.

\subsection{Perdas e Mudanças}

A idade avançada traz consigo perdas e mudanças em situações dolorosas que se sucedem rapidamente. Muitas dessas perdas vão minando a imagem reforçada pela sociedade de parecerem jovens e saudáveis imortais. Algumas dessas mudanças são de natureza física, tais como doenças ou agravos de saúde. A chegada da idade avançada se associa com saúde debilitada e incapacidade e se estima que a mulher enfrente maiores problemas de saúde e doenças crônicas do que os homens (MEHDIZADEH, 2002). Por exemplo, o câncer do seio ataca uma a cada nove mulheres, com a ameaça de cirurgia ou morte; estima-se que cerca de $40 \%$ das mulheres tenham se submetido a uma histerectomia ao chegar à idade de 60 anos e as demais se tornaram estéreis na menopausa; a maioria das pessoas de 65 anos e mais diminui sua capacidade física através de mudanças normais do processo de envelhecimento ou de doenças ou acidentes. Camacho; Strawbridge; Cohen; Kaplan (1993) verificaram que nos Estados Unidos 70\% das mulheres acima de 80 anos tinham uma ou mais dos seguintes problemas crônicos de saúde: artrite, câncer, catarata, diabetes, problemas cardíacos, fratura de cadeiras, hipertensão, osteoporose, acidentes vascular cerebral e varizes. Pressupõe-se que os problemas de saúde estejam associados, em parte, ao nível sócio-econômico baixo.

A etapa do ninho vazio, quando os filhos ou filhas saem de casa, é um período em que muitas mulheres experimentam sentimentos de depressão e de perda, relacionados ao crescimento de seus filhos e à even- 
tual saída destes de casa. Para a mulher, que dedicou sua vida e suas energias para sua família e na criação dos filhos ou filhas, necessitar redirecioná-la torna-se ameaçador. Quando sua tarefa principal de mãe e provedora desaparece, isso pode representar, para muitas mulheres, um sentimento de perda, particularmente quando a criação dos filhos(as) foi a tarefa principal e não foi planejado o que fazer depois. Para outras, pode representar um sentimento de satisfação, de ter realizado um bom trabalho ou ao menos ter cumprido sua obrigação (SANCHEZ, 2000).

Nessa etapa da vida da mulher, também outras relações importantes podem terminar ou mudar. Os esposos ou companheiros morrem ou, com o divórcio, passam a viver com mulheres mais jovens. Três de cada quatro mulheres ficam viúvas, e as possibilidades de casarem novamente são baixas e diminuem com a idade. As amizades também mudam ou desaparecem, seja por morte ou mudança. Outra mudança é a dependência ou morte dos pais. Exatamente quando acabaram de criar os filhos ou filhas, surge a necessidade de cuidarem dos pais ou mães que se tornam dependentes por condições físicas ou mentais. Isso vem, muitas vezes, junto com a grande possibilidade de os mesmos necessitarem de cuidado por um grande espaço de tempo, comprometendo o que restou do tempo que poderia ser dedicado a outras tarefas. Nos Estados Unidos, estima-se que, hoje em dia, as mulheres passam em torno de 18 anos cuidando de seus pais, mais do que o tempo que cuidaram de seus filhos ou filhas.

Um aumento da expectativa de vida da mulher também traz como consequiência maior possibilidade de que, hoje em dia, viva mais tempo como avó. Devido as mudanças sociais ocorridas em nossa sociedade, o papel de auxílio exercido pela avó vem adquirindo maior notoriedade e importância, além de uma contínua ascensão. As avós exercem uma função importante dentro do sistema familiar amplo, provendo uma gama de apoio tanto aos filhos(as) quanto aos netos(as). Esta função de avó serve de meio para a expansão da identidade social e pessoal. Tem-se verificado que ser avó satisfaz plenamente a uma necessidade para a criatividade, realização e competência e dá estrutura e estabilidade à vida de muitas mulheres (HODGSON, 1992; COX, 2000). Como conseqüência também do aumento da expectativa de vida da mulher, haverá o surgimento de relações intergeracionais de larga duração, já que, por exemplo, os netos ou netas poderão ter a oportunidade de conhecer e 
estar por mais tempo com suas avós, pois estas viverão por mais tempo. Isso vai levar ao desenvolvimento de novas relações entre avós e netos ou netas, que redundarão em benefício para ambas as partes.

\subsection{O Lado Positivo}

Contrário ao que comumente se acredita, este período de vida pode ser tão ou mais frutífero e agradável do que o resto da vida de muitas mulheres. Viver ou estar só não significa sempre que uma mulher idosa esteja em solidão. A habilidade que as mulheres têm em estabelecer e manter amizades e de desfrutá-las, desenvolvem bem em toda a sua vida e, particularmente, na velhice. Essa capacidade para estabelecer e manter amizades e relações com familiares, amigos, vizinhos e outros, pode ser uma adaptação à solidão da velhice. Pode ser uma maneira de dar um sentido de identidade positivo e de desenvolver novos papéis. Muitas mulheres entre os 55 e 65 anos realizam avaliações de suas vidas e decidem utilizar seu tempo e habilidades de novas formas. Essa onda de energia pode surgir ao desobrigar-se de quase duas décadas de "criação de filhos ou filhas" e ao usar o tempo liberado para uma mudança de perspectiva. $\mathrm{O}$ aumento da longevidade dá também à mulher a oportunidade de mudar de trabalho, de profissão, de um novo casamento e outras oportunidades educacionais. As mulheres, em particular, tem maior flexibilidade de funções devido a sua maior expectativa de vida. Quando os filhos saem de casa, são mais hábeis em combinar as tarefas familiares com o trabalho, a recreação e a participação em atividades comunitárias. Outro aspecto positivo desse aumento de mulheres em idade avançada está relacionado à necessidade de tirar vantagem disso, demandando a criação e lutando por programas e serviços que respondam às necessidade das mulheres de meia idade e das velhas.

\section{Conclusão}

Infelizmente, as mulheres idosas continuam sendo parte de uma maioria invisível cujas preocupações emocionais, econômicas e físicas permanecem, em grande parte, ignoradas. Às desigualdades sociais, políticas e econômicas que são enfrentadas por todas as mulheres se agre- 
ga, à mulher idosa, a discriminação pela idade, que caracteriza uma sociedade orientada para a juventude. É difícil entender a falta de atenção aos problemas da mulher idosa quando vemos que a transformação social e econômica que acompanha o envelhecimento de uma sociedade está relacionada particularmente com a mulher. A mesma sociedade que cultua o jovem e enfatiza a importância do homem faz com que se preste pouca atenção à mulher idosa. Tendo em vista que a velhice é um assunto de mulheres, deve-se, portanto, trabalhar-se no presente para o futuro. Uma das formas que as mulheres podem utilizar para benefício próprio são as suas redes de apoio. Os grupos de apoio e de discussão podem ser alternativas a se considerar, quer com o fortalecimento dos existentes ou com a formação de novos.

Não resta dúvida de que a sociedade atual se depara com um segmento populacional que está aumentando e que, por sua vez, é vulnerável. Isso tem sérias implicações para os profissionais de ajuda e para os formuladores de política pública. As políticas sociais devem voltar-se para garantir uma renda mínima para a subsistência econômica das mulheres de idade avançada. O recebimento de um rendimento nessa idade deve ser um direito e não uma recompensa por ter trabalhado fora de casa e ter contribuído para um sistema de aposentadoria. Deve-se criar um sistema de saúde universal que garanta serviços médicos a todas as mulheres idosas independente de seus rendimentos. Deve-se oportunizar emprego, em particular a estas donas de casa que têm sido marginalizadas, e programas educacionais para viúvas.

Sugere-se a criação de programas destinados a prevenir a dependência. Nesse sentido, cabe lembrar que a família tem suprido o vazio que os programas de governo não atendem. Mas nem sempre existe uma família disponível, pois muitas mulheres idosas nunca tiveram filhos ou nunca se casaram e seu sistema de apoio familiar é quase inexistente.

Resumindo, os assuntos como solidão, pobreza, mudanças sociais e saúde dentre outros, são realidades e mitos na vidas de muitas mulheres idosas que vivem em uma sociedade sexista e gerofóbica. É responsabilidade dos profissionais da saúde e da gerontologia estarem alertas às situações dessas mulheres na sociedade atual, de forma que possam estar preparados(as) para escutar seus pedidos e legitimar e corrigir a realidade das injustiças e tensões na vida das mesmas. 


\section{Referências}

1 ARBER, S.; GRINN, J. Gender and Later Life. London: Sage, 1991.

2 BEAUVOIR, S. La Vejez. Traducción de Aurora Hernández. México: Editorial Hermes, 1990.

3 BUTLER, R.; LEWIS, M.; SUNDERLAND, T. Aging and Mental Health: positive psychosocial and biomedical approaches. New York: Macmillan, 1991.

4 CALASANTI, T. Gender and Life Satisfaction in Retirement: an assesment of the male model. Journal of Gerontology: Social Sciences, Washington, DC, n. 51B, p. S18-S19, 1996.

5 CAMACHO, T.; STRAWBRIDGE, W.; COHEN, R.; KAPLAN, G. Functional Abilities in the Oldest Old. Journal of Aging and Health, London, v. 5, n. 4, p. 439-454, 1993.

6 CARNIVALI, J. Mujer y edad avanzada: condiciones de salud de la población femenina de edad avanzada de Puerto Rico. P R Health Sciences Journal, San Juan, v. 9, p. 131-136, 1990.

7 COX, B. Carole. To Grandmother's House We Go and Stay: perspectives on custodial grandparents. New York: Springer, 2000.

8 COX, H. Later Life: the realities of aging. New Jersey: Prentice Hall, 1988.

9 GREENBERG, S.; KOPITO, A. Women Growing Older: partnerships for change. In: PRAVDER, M. (Ed.). Women in Context: toward a feminist reconstruction of psychotherapy. New York: Guilford, 1994. p. 96-117.

10 HODGSON, L G. Adult Grandparent and their Grandchildren: the enduring bond. International Journal of Aging Human Development, Amityville, n. 34, p. 209-225, 1992.

11 LESNOFF-CARAVAGLIA, G. The World of the Older Woman. New York: Human Sciences, 1984.

12 MEHDIZADEH, S. Health and Long-Term Care Use Trajectories of Older Disabled Women. The Gerontologist, Washington, DC, v. 42, n. 3, p. 304-313, 2002.

13 NACIONES UNIDAS. Agening. Disponível em: < httm/www.poping.org/ pop 1998/8.htm>.

14 PALO-STOLLER, E; CAMPBELL, R. Worlds of Difference. Thousand Oaks: Pine Forge Press, 1994.

15 PINQUART, M; SORENSEN, S. Gender Differences in Self-Concept and Psychologic Well-Being in Old Age: a meta-analysis. Journal of Gerontology Psychological Sciences, Waltham, v. 56B, n. 4, p. 195-213, 2001. 
16 SÁNCHEZ, C. D. Femenización de la vejez en Puerto Rico. Puerto Rico Health and Sciences Journal, San Juan, v. 17, n. 1, p. 49-53, 1999.

17 SÁNCHEZ, C. D. Política pública y mujer de edad avanzada. Puerto Rico Health Sciences Journal, San Juan, v. 9, p.137-140, 1990.

18 SÁNCHEZ, C. D. Gerontología Social. Buenos Aires: Espacio Editorial, 2000.

19 TURMER, B; TROLL, L. Women Growing Older. Thousand Oaks, CAL: Sage, 1994. 